
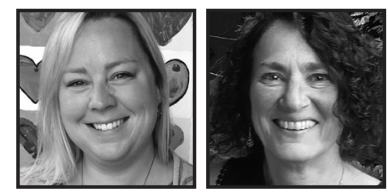

\title{
Valuing Creative Engagement: Transforming Assessment Practices for the Arts
}

\author{
Shannon Lim and Kathy Sanford
}

\begin{abstract}
Two educators explore issues related to arts-based education and assessment. Our students are being short-changed, we believe, when they are not given opportunities to appreciate the arts, to value the richness they bring to our lives and an understanding of the world. We believe that education needs to rebalance the ways in which children spend their time, how they are assessed, and what is valued. We also believe that deepening our understanding and awareness of how we value and assess the arts will deepen and strengthen the way we understand and value all types of knowledge and interactions in the world.
\end{abstract}

$t$ is June. It is June in a year in which our district has imposed a new system for assessment and communicating student learning that should ideally still be in pilot project mode, and June in a school year where summer weather seems to have started in April or May... I look around and see a lot of mixed emotions. Excitement for the summer holidays, the great successes of student achievement over the year, the transition of our grade 8 s to high school in the fall and general passion for the profession. Confusion over what needs to be done before year end, how and where are we recording student achievement, what next year might look like and how on earth we are going to keep students engaged in school activities when report cards need to be submitted on June 15th. Fatigue from long days, extra hours, parent meetings, student discipline, reporting on learning, the heat, year-end activities, and much more. Joy as students wrap up a year and reminisce about great experiences. Sadness and loss as some colleagues move to other schools, retire, or are not hired back due to staffing procedures. I even feel a little bit lucky as I watch other people pack up their rooms in preparation to move spaces, as I hide 
out in my art room, a space that feels calm, quiet, and secure. To say there is a lot happening in schools during the month of June is an understatement. June is certainly more hectic and busy than December.

As we entered discussion around final assessments and what this would look like at middle school in our district this year, I began to question and critique my own practices in my classroom. This year I taught art to all the grade 6, 7, and 8 students in our school. In conjunction with the district expectations and requirements for "exploration assessment" and "communication of student learning," I ended the year feeling as though there was much room for improvement. There was a disconnect between the district expectation and what I was doing with my students in the final art expo. It all felt ineffective to me as a whole. There are parts of the new system that are ideal for certain subject areas, and also for year-long continuous communication with parents, however, in my opinion, as a middle years teacher of an "exploratory" subject (art) it is not suitable or supportive of our curricular areas. For the majority of the year we sent standard exploration rubrics home in paper format, which were never documented at a district level. So, for all those students there is no record of their achievement for the year. At this point I do not have an opinion on whether or not this is important at the middle school level, but in consideration of the time, energy, and outcomes, I feel like the system failed. Maybe I failed. I asked for guidance, looked for support, and kept being told: "we will get to expository classes later," "we haven't got that in the online system yet," "just make sure you get the rubrics out"... In the end, the most valuable piece for me in the art room is students creating, trying new outlets, being open to the arts. How do I measure this?

In discussion with other teachers of exploratory subjects it appears we are all feeling the same way. The rubrics we used were generalized-they mentioned nothing about the elements of art. They do not speak to individuals. Overall, the assessment practices this school year left us feeling undervalued, and if this is how we are feeling as educators, I can only assume our students recognized this as well. I could go on about the problems or concerns I have, but rather, I would like to look at what I can do differently in the future, and plan for next year. I am searching for change, ideas, and positive possibilities for better approaches to assessing my students' progress and development. As I clean up the art room I realize I do not want piles of student creations left behind, I want them to share what they are doing as they make it. I realize that just because teachers in the past have used portfolios, which were always left in the room as a means of assessment for student artwork, this does not mean that I am tied to the system. Students should be able to share their creativity, display their work at school and home, and we can look at other ways of visually documenting their achievements. At the end of this school year I find myself looking for change, creative communication, and clear objectives when it comes to assessment practices in the art exploration area. 
It was this reflection of S's practice that caused further discussions between her, a classroom teacher, and $\mathrm{K}$, a university instructor-both interested in exploring ways to value the art in all children's lives, examine ways in which we value (or not) artsbased learning, and determine appropriate assessment practices for art and all creative engagement. We began an exploration into the recognition and utilization of art and visual media as critical elements of learning for today's children and youth, but still not being seen as valuable or valued aspects of children's learning experiences in our schooling system. And through our journey we have recognized that not only is this discussion pertinent to assessment in art, but can also be extrapolated, we think, to all forms of student learning. In this paper we will talk about the importance of the arts in childrens' and youths' lives, how our current understanding and practices of assessment are not adequate for supporting learning, and finally, we will share examples of ways to better assess and value students' works of art, both in process and final "product."

Arts have consistently been undervalued in our competitive, content-focused, neoliberal world, driven by notions of entrepreneurship and capitalism. This has impacted our interest in and acknowledgement of visual forms of expression more broadly, which have often been limited to a cursory nod and bland platitudes, as S's beginning story suggests. The power of the arts, and visual media more specifically, to make meaning, to engage learners, to share understandings and to enrich our experiences, have been overlooked in a system driven by literacy (i.e., reading print text) and numeracy. And while we would suggest that assessment has overall been disconnected from learning, this is most evident in the arts. Freedman and Stuhr (2004) have:

argued for a transformation of art education in response to changing conditions in the contemporary world where the visual arts, including popular arts and contemporary fine art, are an increasingly important part of the larger visual culture that surrounds and shapes our daily lives. (p. 815)

This affirms S's value as an art educator, and reaffirms the importance of what students experience in the art room, but also causes her to reflect upon how to align what happens with instruction in the arts in connection to current assessment practices implemented in schools. The lack of attention to the arts and visual modes of learning and communicating has resulted in less focus on development of meaningful and robust assessment practices in these areas. Freedman and Stuhr note, 
If the intention of education is to prepare students for personal fulfillment and to constructively contribute to society, then art education must deal with newly emerging ideas, problems, and possibilities that go beyond the constraints of learning offered by a discipline-based curriculum and standardized forms of assessment. (p. 816)

However, while Ross (1986) claims that examination in the arts is both "impracticable and undesirable" (p. 124), Eisner (1974) suggests that it would be educationally irresponsible for teachers not to assess students' artwork and that "as teachers we are concerned not simply with bringing about change, but with bringing about desirable change" (p. 13) in students' work. In education, with many pressures and demands, recognizing the bigger picture or importance of student experiences, artistic and beyond, to their connection in the world and their future is often or easily forgotten. Stepping back and identifying what really matters or counts is essential. Recognizing an integral relationship between assessment and curriculum, where both must be of high quality, is essential for meaningful art-based experiences.

\section{Importance of Arts}

The value of engaging meaningfully in understanding, creating, and assessing art cannot be overstated. Art has a unique way of connecting us to our inner selves, to our younger selves, and to our future selves in powerful ways. Freedman and Stuhr (2004) comment,

Visual culture is a mode of experience that connects people through many and varied mediators. The variety and complexity of the experience are dependent on the possibility of a range of quality related to form, none of which should be inherently excluded from the investigation, analysis, and critique enabled by art education. Even concepts and objects previously considered fairly stable are in flux. Truth has shifted from an epistemological to an ontological issue: That is, it becomes less about what we know than who we are. Time has lost its neat linearity, space appears to expand and contract, and boundaries of various sorts have become blurred. Perhaps most important, postmodern visual culture makes imperative a connectedness that undermines knowledge as traditionally taught in school. It involves interactions among people, cultures, forms of representation, and professional disciplines. (p. 819) 
Learning is both individual and social. It is about people, exploration, communication, and interaction. We are all unique in our learning journey, suggesting that assessment practices should be adaptable and allowed to meet those needs well. It is about who we are, the materials used, the experience lived. Of course, there are expectations and standards that need to be recognized within the context, however it must also be recognized that the world around us is changing and we ourselves are not fixed. Freedman and Stuhr (2004) suggest that students' art experience "is essential to teaching and learning about visual culture because it (a) is a process of creative/critical inquiry, (b) helps students understand the complexities of visual culture, and (c) connects and empowers people" (p. 825).

\section{Importance of Assessment}

If students' artwork is not shared, discussed, acknowledged, and displayed, there is little interaction and engagement that is essential to art. Not only should art be created, but it also needs to be discussed with students during and after the creation processnot just after the work has been completed, but also during the process, valuing the thinking and skills used in the creation, as well as challenges encountered along the way. "Learning to make art," Barrett (2004) comments, "does not necessarily transfer to appreciating or enjoying art." She continues:

Learning to make art does not necessarily transfer to learning to infer meaning in art, especially art made by artists other than oneself. Therefore, learning to talk thoughtfully about art is especially valuable, perhaps more valuable than learning to make art. Learning to interpret meanings of works of art is more valuable than learning to judge their value. An artwork that is not interpreted is reduced to a mere object. (p. 87)

How do we resist seeing students' art as "mere object"? If work is not shared, discussed, displayed, and taken in, there is no interaction and engagement that is essential to appreciation and understanding of art. This suggests the important role assessment has to play in shaping and strengthening the learning as art is created, assessment that is supportive, encouraging, and informative. Reconceptualizing assessment as a moment of learning allows teachers to see it in terms of authentic artistic processes such as setting goals, assessing one's own work, and revising-processes that are inherent in any creative endeavor that involves rehearsal and redoing (Zessoules \& Gardner, 1991). Teachers must turn 
their attention to more clearly articulating their expectations for their students and help them to reach those expectations and understand the goals they are setting with the teacher. As Andrade, Hefferen, and Palma (2014) noted, "Classroom assessment is a hot topic in K-12 education because of compelling evidence that assessment in the form of feedback is a powerful teaching and learning tool" (p. 34). As conceptions of curriculum and assessment are being reshaped across Canada, we are focusing more clearly on alternative forms of assessment practices, including assessment that involves students in their own learning, opening up conversations with students around making art, learning, and creating. Communication is essential. Andrade et al. (2014) suggests that students benefit from three simple things: "(1) An understanding of the targets or goals for their learning; (2) knowledge of the gap between those goals and their current state; and (3) knowing how to close the gap through relearning and revision" (p. 34). If students are involved in their own learning they are connected, accountable, and able to move forward. Learning is far more meaningful when targets or goals are set.

\section{Assessing Art: What and How Are We Assessing?}

What are we assessing? According to Lauchlan (2012), the goals for assessment should be clarified first, before anything else is established and the learning process has begun. He also goes on to remind us of the importance of keeping our goals to support the teaching and learning process at the forefront of our thoughts when designing assessment plans. This is essential to effective planning, keeping assessment for learning at the forefront, rather than summatively evaluating student work, that is, assessment of their learning (Earl, 2003) - having to sift through student work after they have completed it, trying to decipher and interpret what is valuable and worth reporting on, what they know and still need to work on. A checklist of questions, shared with students, is beneficial for reminding teachers and students of the role that assessment plays in learning throughout the process. Some questions that might be asked by teachers include:

- Why is the assessment happening?

- What is the end goal for the assessment?

- How will it be shared or communicated? And with whom?

- What kind of information is necessary?

- What is the long-term impact of the assessment or connection to other areas in the curriculum?

- In what ways will this assessment guide or inform the student's future learning?

- How does the assessment impact the teaching and learning process? 
Teachers say that they do not assess students simply to assign a letter grade and have them move on to the next task, unit, or assignment. They say that assessment is continuous, ongoing, and reflective and always focused on the learner. Yet, often when it comes down to the practicality of it all, it would appear that we fall back on traditional practices and paper trails. After examining the types of assessment practices evident in K-12 art education today, it is difficult to see how these practices align with goals and intents set by the curriculum or the teachers themselves. Feedback is a valuable aspect of learning in the arts, but clearer understanding of what that should look like, sound like, and feel like needs to be better developed. However, as Eisner and Day (2008) comment, the field of visual art education is in a bind-on one hand assessment is critical in a climate where educational policies mandate testing of students in all subject areas; on the other, art education values outcomes that are not simply definable or measured, but rather those that are imaginative, diverse, and interesting in many different ways where this is no single criterion that adequately represent students' learning.

Connecting what students are learning to bigger ideas is essential. Moving beyond simply creating a painting for color theory, for example, to exploring social, cultural, and environmental connections can be far more engaging. Allowing for open interpretation, choice, and various responses is key.

Procedures should be user friendly; art tasks should be stimulating and relate to bigger ideas and should have multiple solutions; art programs should be congruent in content and aims; and content should address a variety of sensory and cognitive modes. (Brewer, 2008, p. 64)

Students and their parents might value art more highly if they consider its power: "teaching and learning about visual culture because it (a) is a process of creative/ critical inquiry, (b) helps students understand the complexities of visual culture, and (c) connects and empowers people" (Freedman \& Stuhr, 2004, p. 825). Taking time to communicate these ideas to students would heighten their awareness of art's importance in developing skills, attitudes, and understandings important for life.

Returning to Zessoules and Gardner's (1991) call to reconceptualize assessment as a moment of learning, teachers need to consider how to think about assessment as an aspect of the learning process and to match their practices with their beliefs about learning. How we assess is as important as what we assess. Classes get rushed. Time is at a premium. However, teachers need to take time to build assessment into the process of learning, to work expectations, communication, reflection, and goal setting into the flow of art making. Otherwise it has the potential to become creating 
without meaning, without purpose. However, assessment is not always neat or linear. Willis (2014) suggests that

in assessment, there should be no prescribed point of entry or linear procedure. The individual should enter the assessment labyrinth holistically from any relevant portal. The point of entry is not as important as the multiple referential reflections. The process should reflect the elaborate nature of art assessment and allow flexibility to meet the needs of the image, person, and environment. (p. 150)

Willis' suggestion is completely contrary to the forms of assessment generally utilized in schools today, linear, top-down, and controlled rather than fluid, holistic and an enjoyable part of the learning journey. And while this approach contrasts with current assessment practices in art education and elsewhere, it is an important consideration. Brewer's (2008) comment reaffirms the idea that assessment in art is complex and needs to be different to what currently exists: "The idea of how to credibly assess learning in visual art is elusive and confusing. All art teachers do some sort of assessment, but like art making itself, very few do it the same way or with much consensus" (p. 63). Andrade and colleagues (2014) note that there are "myriad ways in which assessment can not only measure and document student learning but also - and more importantly - actually promote learning" (p. 36). Teachers' expertise needs to be considered in determining assessment practices, and select those most appropriate for their students, their context, and the goals/expectations set for each activity. This, then, requires teachers to use assessment approaches that value learning processes, give time, ensure that focused and meaningful feedback is provided, and that students are invested in their art.

Formative assessment is intended to have subsequent, positive effect on a child's learning through the use of feedback and consultation. There has been increasing recognition that assessment should be used to support learning, rather than merely reporting on a child's current, or past achievement (summative assessment). (Laughlan, 2012, p. 96)

As noted earlier, dialogue and communication with students are important to encouraging and supporting their ongoing learning about art-promoting and fostering ongoing learning as students discuss their work, share, rework, and complete. 


\section{How We Use Assessment in Art}

Involving students in their own learning as they create art is empowering and encouraging of future art-making. As students learn to use art-specific vocabulary and terminology, and as they practice providing meaningful responses to their peers, they learn to assess their own work, recognizing technique, form, media most appropriate for their intents and goals. As Hattie and Timperley (2007) comment,

The ways and manner in which individuals interpret feedback information is the key to developing positive and valuable concepts of self-efficacy about learning, which in turns leads to further learning. Teachers need to view feedback from the perspective of the individuals engaged in the learning and become proactive in providing information addressing the three feedback questions and developing ways for students to ask these questions of themselves. Students, too often, view feedback as the responsibility of someone else, usually teachers, whose job it is to provide feedback information by deciding for the students how well they are going, what the goals are, and what to do next. (p. 101)

As students become more capable of assessing their own work, they will likely be more invested in continuing to improve. They will be able to make connections between art and their own lives, other aspects of their learning (e.g., science, language arts, math, drama, music, to name a few). "Most important, students know how and when to seek and receive feedback from others" (p. 94). Students need to learn to communicate and connect with people. Whether they need support, are looking for answers to their questions, or just want to share their learning, the more open to learning and the people involved in the journey, the more likely they are to value and find success in their art.

\section{Shifting Classroom Assessment Practices}

So that we can broaden our conception of what makes meaningful and significant learning, including art as a meaningful ways of expressing and sharing in order to become holistic learners and people, we now offer several ways of engaging with students in their assessment of their arts-based learning.

Using prompts to stimulate discussion about art. Students need guidance to develop their own formative assessment skills. Their views can be directed and shaped so that they take each work of art seriously and learn more informed appreciation and attention to diverse art forms. Barrett (2004) suggests developing prompts that encourage students to talk about their work. For example, she asks, "Let's see what 
we can say about this work." or "Who would like to get us started?" and then "Who can add to that thought?" (pp. 88-90). In more specific terms, students can be asked to describe works of art: "What do you see?" "Who can add to that?" and from there, "How do you feel when you see that picture?" "What has the artist done to make you feel that way?" "What in the painting/drawing has you feeling that way?" "How do the specific shapes affect the meaning of the painting?" Students can also be asked interpretation prompts, "What is that about?" "What does it mean?" "How do I know?" "What might it mean to the artist?" "How might my experience of this work change my life?" Barrett also suggests prompts about art theory, such as "Why is that art?" All of these prompts encourage students to value the art as meaningful and important, considering art as a valid way of expressing and understanding aspects of the world and their place in it. By developing these specific question prompts, a multiplicity of voices is encouraged, engaging everyone in the discussion. Hearing each other's responses provides immediate and specific feedback about their own and others' work, and develops deeper understanding and valuing of art. Barrett (2004) believes that "when one understands a work, one will likely judge it to be good and also end up enjoying it, which is a highly desirable affective outcome" (p. 92).

\section{Immediate Reflection of Accomplishments: Critique Board}

Discussions and feedback in class with individual students can be some of the most meaningful form of assessment for our learners. Communication that happens in the moment is real, to the point, and says more than a comment offered a day, a week, or months later. The more opportunities created for check-ins and face-to-face interactions with students and their parents, the better. When looking at art-specific assessment, one model is to have more frequent and open critique discussions about individual assignments, display student work more often, and have students share specifics about their work. Creating a "critique board," or common area focused on temporarily displaying artwork in the art room, would help with this and demonstrate to students that this is what artists do: they share their successes and works in progress; they go back and improve on things. Classroom teachers can allow time for discussion, encourage students to share their work, self-assess, look at strategies and techniques to improve their work, alter or change their creations. Full critique sessions might take place one day every two weeks where students put up current assignments, display, discuss and document their progress.

Along with the idea of instant assessment of student artwork that encourages forms of collaborative assessment, students can interview each other about their work, create rubrics, and use more than "complete/incomplete" or just checking it off on 
a list of things that are "done." Using rubrics specific to the arts-created with students, with descriptive language related to the current assignment-would be more meaningful. The ongoing nature of instant assessment provides specific and descriptive feedback to be used in their future learning, rather than merely as a form of judgment and ranking.

\section{Create a Rationale for Learning Linked to Assessment in the Classroom}

By having a rationale evident in the classroom that states why it is important to be doing what they are doing, teachers can refer back to it repeatedly when considering assessment practices. When questioning what, why, and for whom they are assessing, these guiding principles will help keep assessment practices focused, meaningful, and to the point. An example for the art room might look something like this:

\section{The importance of experiencing and learning the visual arts}

In the art room students will combine skills and creative thinking to design and make products that are visually appealing, they will demonstrate the elements of art and principles of design, and express themselves in unique ways. Students will learn to use a variety of materials, be responsible for the maintenance and presentation of the art room space, and respect the right for others to be experiencing and learning the arts as well. They will learn to think creatively, apply it to real life situations, solve problems, and work collaboratively.

By working in a creative space students will experience a range of opportunities, respond with their own ideas to assignments, meet and exceed challenging expectations, and be responsible for their learning journey. They will consider aesthetics, technical problems, cultural, social and emotional influences, as well as environmental concerns. As their learning progresses they will evaluate themselves, be open and accepting of feedback, collaborate with peers and be an integral part of their learning communication. Through their experiences in art, students will gain confidence in their creativity, their technical skills, and apply their creative thinking and expertise to future learning goals and projects. (Based on a passage from Pollitt, 2012)

Long-term portfolio development. Students can develop portfolios of their artwork early in their lives and have these continue throughout their schooling. While this is not a new idea, it is one that has great potential for students who are focusing their learning in specific curricular areas. It would be a powerful learning experience for students to curate their own art show through pieces picked from their middle and 
high school years (or earlier perhaps). Students could be starting portfolios of their best or favourite pieces early on in their educational journeys, and documenting them digitally, adding several times throughout the year, including photos and descriptions. Digital documentation and curation would add new dimensions to students' artistic skills and appreciation for diverse media. A long-term portfolio would also foster collegiality and collaboration between teachers as well, as the student moves from one grade to another. It would help set standards and expectations across the spectrum of years for ways of documenting student artwork. By allowing this continuity teachers would also be improving the entire art experience, validating and giving importance to the arts as a whole, creating a strong community of teachers validating the arts, and creating rigorous meaningful ways of assessing development in the arts.

Creating a general assessment outline. A curriculum-specific outline could be present in the classroom at all times. Students could become familiar with the outline and any artworks or tools that are regularly used. Ongoing reference to this outline would reinforce a deeper understanding of the role that assessment plays in learning about art and specific elements expected for successful learning. It would also reinforce the importance of regular self-assessment. This visible outline would further remind teachers of the goals and expectations in each of their art assignments. This tool would act as a reminder for students to have appropriate tools on hand, to keep track of feedback, and to use guiding points for conversation. The more consistent, familiar, and fluid the process, the greater likelihood that students will respect and value their art creation and learning, enabling them to grow as increasingly proficient and independent learners.

Examples of two possible outlines are shared below, demonstrating the positive formation of reflective elements of the outline. These elements could become increasingly specific as students become more sophisticated artists and art critics. 
Table 1

\section{General Areas of Understanding}

\begin{tabular}{|l|l|l|l|}
\hline GENERAL AREAS OF UNDERSTANDING & YES & NO & COMMENT \\
\hline $\begin{array}{l}\text { Vocabulary: I am using correct vocabulary to } \\
\text { discuss my work. }\end{array}$ & & & \\
\hline $\begin{array}{l}\text { Reflectiveness: I am pausing to reflect upon } \\
\text { my discussion. }\end{array}$ & & & \\
\hline $\begin{array}{l}\text { Nature of responses: I am answering or } \\
\text { discussing with meaning rather than guessing. }\end{array}$ & & & \\
\hline $\begin{array}{l}\text { Exploration: I searched for ways to add more } \\
\text { meaning to my work and I looked for alternate } \\
\text { solutions. }\end{array}$ & & & \\
\hline $\begin{array}{l}\text { Communication: I communicated my work in } \\
\text { a clear and coherent manner. I understand the } \\
\text { principles of art I am applying. }\end{array}$ & & & \\
\hline
\end{tabular}

Table 2

\section{General Areas for Learning}

\begin{tabular}{|l|l|l|l|}
\hline GENERAL AREAS FOR LEARNING & YES & NO & COMMENT \\
\hline $\begin{array}{l}\text { Collaboration: I seek help, and am willing to } \\
\text { become involved in collaborating with other } \\
\text { students. }\end{array}$ & & & \\
\hline $\begin{array}{l}\text { Concentration: I am able to focus and remain } \\
\text { concentrated on my artwork. }\end{array}$ & & & \\
\hline $\begin{array}{l}\text { Flexibility: I am flexible in my use of strategies } \\
\text { when I am working in the art room. }\end{array}$ & & & \\
\hline Motivation: I am keen to be successful. & & & \\
\hline $\begin{array}{l}\text { Vitality and awareness: I respond positively in } \\
\text { class, and come energetic and alert. }\end{array}$ & & & \\
\hline
\end{tabular}


These two examples have five areas to consider, but even these might be too many. Teachers could prioritize different areas at different times. More details could be added and focused on specific tasks and materials in the art room or other classroom settings. As common arts-based language is used and valued, students will begin to focus their energy on these areas; these general headings are areas that will enable students to be successful and fluent in arts processes.

Table 3

Helpful Checklist

\begin{tabular}{l|l|l|}
$\begin{array}{l}\text { AREAS THAT ARE } \\
\text { IMPORTANT FOR OUR } \\
\text { LEARNING: }\end{array}$ & $\begin{array}{l}\text { STRATEGIES WE WILL TRY } \\
\text { OUT IN THE ART ROOM: }\end{array}$ & $\begin{array}{l}\text { HOW WE WILL KNOW IF WE } \\
\text { ARE SUCCESSFUL: }\end{array}$ \\
\hline & & \\
\hline & & \\
\hline
\end{tabular}

Video taping students in the classroom throughout the course. Filming students can be used as an effective tool for self-assessment. By watching themselves on video, students are able to determine changes that could be made to ways in which they use tools, space, and time. Sharing the video with others can help promote creativity and encourage students to take responsibility for their work. As students tend to do more of the things at which they are most successful, watching themselves will help fine-tune their practices.

Public sharing of student work. Encouraging students to take work home once finished, sharing it with family and friends, promotes art as a valued and valuable form of representing knowledge in the classroom and the school. Public displays in the school, in prominent locations, enable students to learn skills of curation and effective ways of displaying artwork in the school. When students make their art accessible to the public, it validates and authenticates both them and art as a significant form of learning and representing. 


\section{Conclusion}

Returning to S's story, we recognize the challenges faced by students and teachers of art in valuing art as an integral aspect of their learning. Reinvigorating creative and critical engagement with their visual creations is essential for holistic learning and learners. Our students are being short-changed when they are not given opportunities to appreciate the arts, to value the richness they bring to our lives and understanding of the world. We believe that education needs to rebalance the ways in which children spend their time, how they are assessed, and what is valued. We also believe that deepening our understanding and awareness of how we value and assess the arts will deepen and strengthen the way we understand and value all types of knowledge and interactions in the world. We leave the reader with S's final words, gaining hope and stamina through this exploration to continue defending the need for the arts in all students' lives.

My question is, what do our students take away from all this? We give feedback, we write comments, we collaborate on self-assessment, and we communicate on student learning in many other ways. Teachers end up with lists, copies, data entries, notes, folders and all sorts of findings. But what do students really take away from it all? How are we affecting their learning for the future with assessment done today? What are they going to remember about their learning in a year, two, or five? What will they look back and appreciate in 20 years? I don't know the answer. It is in constant change, and we are always adapting to circumstance, technology, and change. I question this because I feel like the answer, or part of the answer, will help guide good, effective, and meaningful assessment practices. Not only assessment in art, but also across the curriculum areas. What is lasting about what we are doing with regards to assessment? What meaning and purpose does it all have?

I consider positive relationships and communication to be of utmost importance in the classroom. In connection to feedback, and the power of words, these thoughts together have the potential to be really influential in a learner's experience. As a teacher, I can see that we need to have a connection with our students for feedback to be valued or for rubrics to be useful. The descriptors in our rubrics need to be co-created with the voice of students alongside the teacher. This reinforces the value and relevance of our assessment. "Thinking of individuals as crystals with many facets may capture the complexity of assessing the visual arts" (Willis, 2014, p.149). This image captures the uniqueness and individuality that is connected with assessment, especially in the arts. There is so much personal interpretation related to creativity and expression, so many layers, facets, and dimensions. The crystal is something that stands alone, but also touches everything it comes into contact with, both reflecting and absorbing at the same time. 
Slowly I am gathering alternative options for assessment, keeping in mind and questioning the value and meaning of it all. I am searching for assessment with purpose for students and educators.

\section{References}

Andrade, H., Hefferen, J., \& Palma, M. (2014). Formative assessment in the visual arts. Art Education, 67(1), 34.

Barrett, T. (2004). Improving student dialogue about art. Teaching Artist Journal, 2(2), 87-94. doi:10.1207/s1541180xtaj0202_3

Brewer, T. M. (2008). Developing a bundled visual arts assessment model. Visual Arts Research, 34(1), 63-74.

Earl, L. (2003). Assessment as learning: Using classroom assessment to maximize student learning. Thousand Oaks, California: Corwin Press.

Eisner, E. (1974). Examining some myths in art education, Studies in Art Education, 15(3), 7-15.

Eisner, E., \& Day, M. (2008). Handbook of research and policy in art education. Mahwah, $\mathrm{NJ}$ : Lawrence Erlbaum Associates Publishers.

Freedman, K., \& Stuhr, P. (2004). Curriculum change for the 21st century: Visual culture in art education. Handbook of Research and Policy in Art Education, 815-828.
Hattie, J., \& Timperley, H. (2007). The power of feedback. Review of Educational Research, 77(1), 81-112. doi:10.3102/003465430298487

Lauchlan, F. (2012). Improving learning through dynamic assessment. Australian Educational and Developmental Psychologist, 29(2), 95-106. doi:10.1017/edp.2012.13

Pollitt, A. (2012). Comparative judgement for assessment. International Journal of Technology and Design Education, 22(2), 157-170. doi:10.1007/s10798-011-9189-x

Ross, M. (1986). Against assessment. In M. Ross (Ed). Assessment in Arts Education. Oxford: Pergamon.

Willis, S. (2014). Crystalline awareness: A suggestion for arts assessment. Visual Arts Research, 40(1), 149-152.

Zessoules, R., \& Gardner, H. (1991). Authentic assessment: Beyond the buzzword and into the classroom. In V. Perrone (Ed.), Expanding student assessment (pp. 47-71). Alexandria, VA: Association for Supervision and Curriculum Development. 


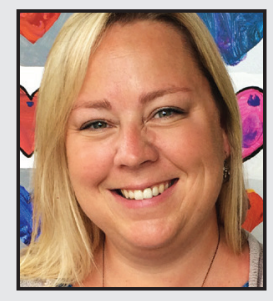

Shannon Lim currently teaches and creates art in the very same school and classroom where she spent her days as a middle school learner many years ago. She works with her students in a variety of mediums, allows for hands-on learning experiences, and believes in the positive benefits of creative engagement of students. Shannon feels fortunate to build upon her community roots and connections, fostering positive relationships with her students, and takes pride in igniting the curious spark and creative energy of young adults. She has a degree in Graphic Design (NSCAD), Bachelors of Education (VIU), and a Masters in Curricular Studies (UVIC).

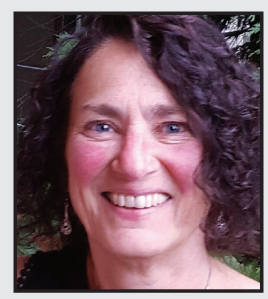

Kathy Sanford is a Professor in the Faculty of Education at the University of Victoria. Her research interests include assessment, digital portfolios, nonformal and informal adult education, teacher education, gender pedagogy, and multiliteracies. She is currently working on research focused on alternative spaces and places for learning, learning in professional programs, video games and youth civic engagement, museum/library education, and e-Portfolio development in three professional programs. Recent publications include Creating Dialogue and Unschooling Education, and she has co-authored Women, Adult Education and Activism in Public Art Galleries and Museums. 